\title{
Reconstructing Rock Art Fe-oxide Pigment Pyrotechnology Using In Situ SEM Heating Experiments
}

Brandi L. MacDonald ${ }^{1}$, David Stalla ${ }^{2}$, Xiaoqing $\mathrm{He}^{2}$, Matthew R. Maschmann ${ }^{3}$, David Emerson ${ }^{4}$, Tommi A. White ${ }^{2}$

${ }^{1}$ Archaeometry Laboratory, University of Missouri Research Reactor, Columbia, MO 65211

${ }^{2}$ Electron Microscopy Core, University of Missouri, Columbia, MO 65211

${ }^{3}$ Mechanical and Aerospace Engineering, University of Missouri, Columbia, MO 65211

${ }^{4}$ Bigelow Laboratory for Ocean Sciences, East Boothbay, ME 04544

Red pigments composed of Fe-oxides, commonly referred to as ochre, are the most frequently found paint types used to produce rock art throughout human history. Ubiquitous in the environment, $\mathrm{Fe}-$ oxides form many mineral polymorphs including hematite $\left(\mathrm{Fe}_{2} \mathrm{O}_{3}\right)$, goethite, $(\mathrm{FeO}[\mathrm{OH}]), \mathrm{FeO}$, and others. Examination of pigment from a rock painting (Babine Lake, BC, Canada) revealed evidence for the use of biogenically-derived Fe-oxide. The presence of structural and melt-phase features also suggest that the pigment was thermally altered to achieve a desired hue. Our results indicate that at Babine Lake, hunter-gatherers harvested and fired microbial mats dominated by the Fe-oxidizing bacterium (FeOB) Leptothrix ochracea to produce red pigment.

Initial examination indicated that the mineral colorant was produced by L. ochracea [Fig. 1], an aquatic bio-mineralizing chemolithotrophic microbe that is common in circumneutral $\mathrm{pH}$ habitats, including lakes, ponds, and wetlands where ferrous iron ( $\mathrm{Fe}(\mathrm{II}))$ is abundant [1]. L. ochracea proliferate by oxidizing ferrous ions to ferric oxides, and precipitate distinctive sheath-like structures of poorly crystalline Fe-oxyhydroxides that contain a fibrillar organic matrix [2]. L. ochracea sheaths are a complex, highly thermostable, organic-inorganic hybrid nanocomposite (Fe:Si:P, plus O, C, and H).

To assess whether the rock art pigment was thermally enhanced required comparative analysis of control samples. Non-crystalline Fe-oxide mineral phases readily crystalize to $\alpha-\mathrm{Fe}_{2} \mathrm{O}_{3} \sim 300^{\circ} \mathrm{C}$, yet a minimum of $600^{\circ} \mathrm{C}$ is required to induce similar phase transitions in L. ochracea [3]. To evaluate these transitions we obtained fresh-collected microbial mats containing L. ochracea and conducted controlled firing experiments in a muffle furnace at $200^{\circ} \mathrm{C}$ intervals from ambient through to $1,000^{\circ} \mathrm{C}$ (Fig. 2), as well as continuous SEM in situ heating using Protochips Fusion ${ }^{\mathrm{TM}}$ technology (Protochips Aduro 350). We observed key morphological and phase transformations. Below $400^{\circ} \mathrm{C}$, few structural changes occur. Between $600^{\circ} \mathrm{C}-700^{\circ} \mathrm{C}$, we observed fraying of exterior organic fibrils, and melt-induced phase separation of the Fe:Si nanocomposite structures. The Fe:Si bonds begin to break down, and the ions rearrange and nucleate the formation of globular hematite and silica microspheres. At $600^{\circ} \mathrm{C}$ the $\mathrm{FeOB}$ are rapidly oxidized, enhancing their color from brown-orange to a vivid red in visible light. At $800^{\circ} \mathrm{C}$, sheaths begin to lose structural integrity by slumping, warping, and mass shrinkage due to water loss. By $1,000^{\circ} \mathrm{C}$, complete phase transition of amorphous Fe-oxide to crystalline polymorphs occurred, and the pigment color converted from vivid red to charred black.

Comparison to rock art: the FeOB sheaths in the rock art sample show obvious signs of pulverization to be expected in a homogenized powder, including fractured sheaths oriented in multiple directions. The exterior sheath surfaces show evidence of partial melting and Fe:Si phase separation, proliferation of hematite spheres, and incomplete formation of magnetite crystals. Based on these comparative features, 
we argue that the FeOB pigment used for the rock art was deliberately subjected to controlled thermal alteration at a minimum of $600^{\circ} \mathrm{C}$, though no greater than $1,000^{\circ} \mathrm{C}$. This step in the pigment preparation sequence would have rapidly induced oxidation and phase separation in the FeOB mass, and perhaps most importantly, would have achieved the intended goal of intensifying the pigment color from orangebrown to the vivid red seen in the rock art glyphs [4].

\section{References}

[1] Suzuki et al. Applied Environmental Biology, 77 (2011) p. 7873-7875.

[2] Fortin and Langley, Earth Science Reviews 72 (2005) p. 1-19.

[3] Hashimoto et al, Dyes and Pigments 95 (2012) p. 639-643.

[4] This research was supported by University of Missouri EMCore Excellence in Electron Microscopy Awards (MacDonald); NSF-MRI ECS-0619607 (University of Missouri Electron Microscopy Core Facility), and in part by NSF-1621168 (Archaeometry Lab, University of Missouri Research Reactor).
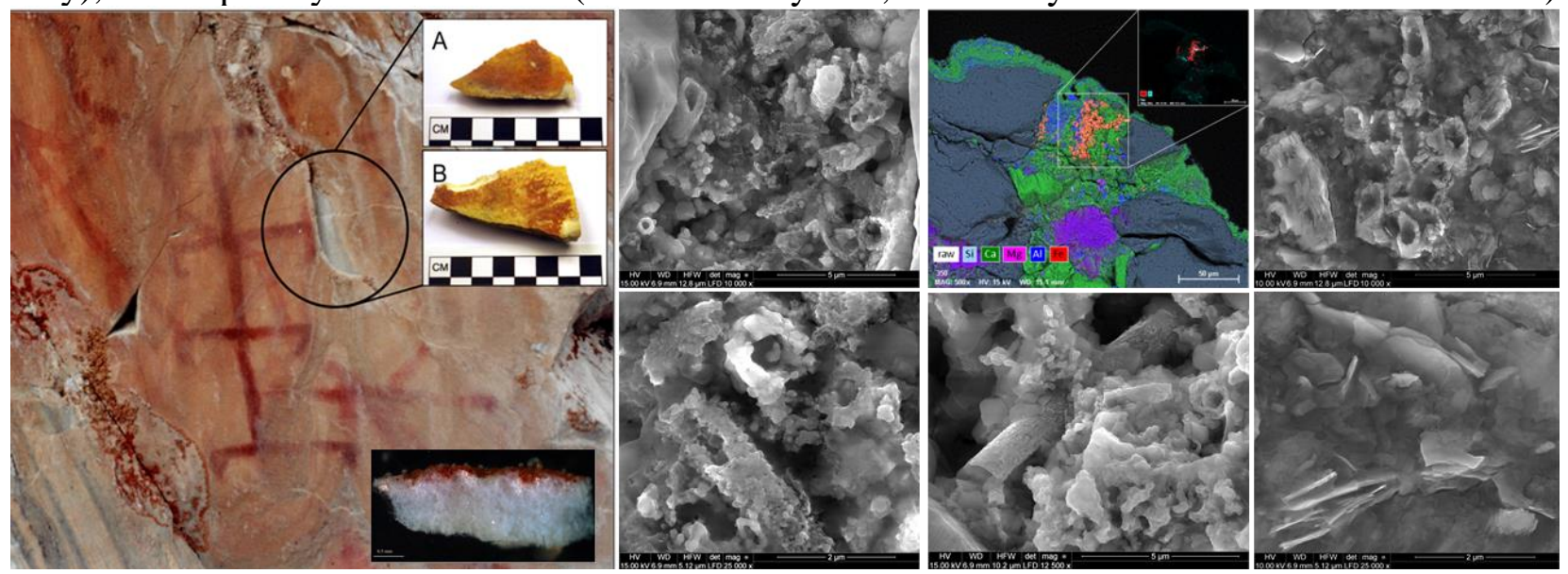

Figure 1. Left: Image of rock art samples; middle, right: SEM micrographs highlighting melt features, hematite spheres, octahedral hematite polymorphs, and fractured and randomly oriented sheaths.

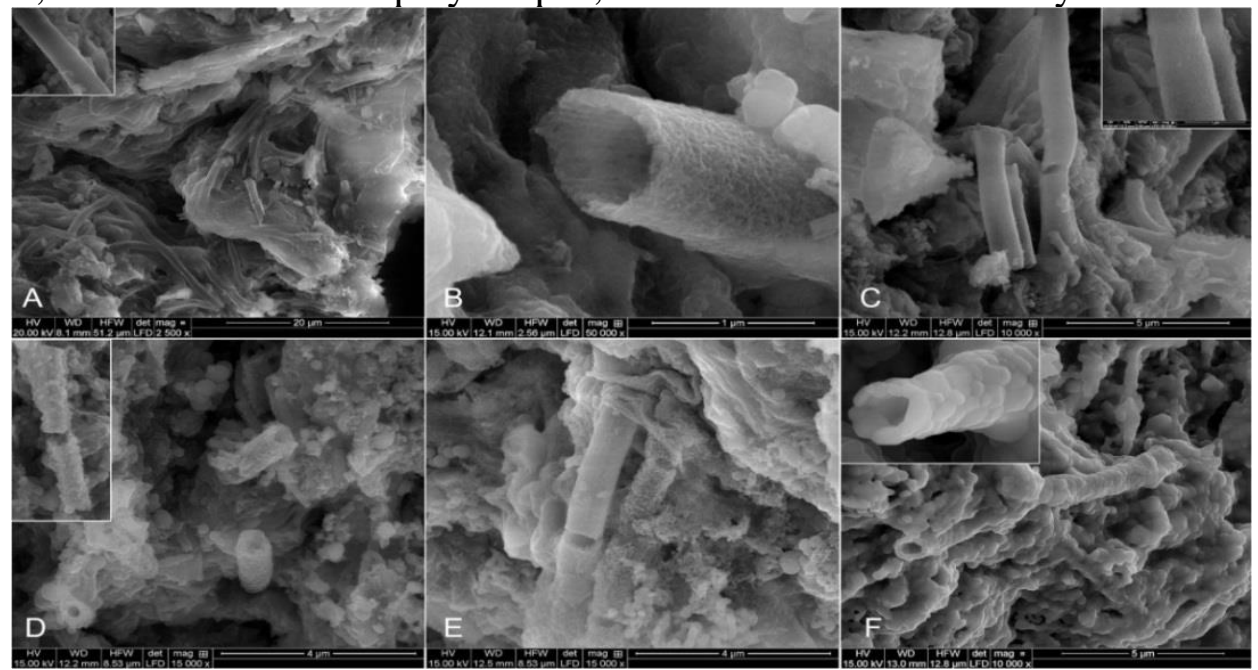

Figure 2. L. ochracea control samples: (A) unfired, note the microcolony clusters, unidirectional in growth, smooth exterior texture; (B) $200^{\circ} \mathrm{C}$; (C) $400^{\circ} \mathrm{C}$; (D) $600^{\circ} \mathrm{C}$ : structural changes including fraying of sheath exteriors, initial Fe:Si phase separation; (E) $800^{\circ} \mathrm{C}$, note melt features on sheath exterior surfaces, nucleation of hematite spheres; (F) $1,000^{\circ} \mathrm{C}$, complete phase transformation to crystalline magnetite $\left(\mathrm{Fe}_{3} \mathrm{O}_{4}\right)$ and octahedral hematite $\left(\mathrm{FeO}_{6}\right)$ polymorphs. 